\title{
The fate of faecal pellets in the North Sea
}

\author{
Peter Martens ${ }^{1} \&$ Michael Krause ${ }^{2}$ \\ ${ }^{1}$ Biologische Anstalt Helgoland (Wadden Sea Institute Sylt); D-2282 List, FRG \\ ${ }^{2}$ Institut für Allgemeine Botanik, Ohnhorststraße 18; D-2000 Hamburg, FRG
}

\begin{abstract}
During an intensive survey in May/June 1986, 129 stations in the North Sea were examined in different water depths with respect to several hydrographical parameters. The relations of planktonic faecal pellets to food (chl-a) and producers (zooplankton-wet weight) as well as to temperature, salinity and water depth were investigated. The amount of faecal pellets was positively correlated with chl-a and zooplankton. The length of the faecal pellets was negatively correlated with water depth indicating a degradation during sinking. Hardly any formed faecal material was detectable under $100 \mathrm{~m}$ water depth. The ratio of pellets to zooplankton was positively correlated to chlorophyll and influenced by daytime, indicating diel variations in pellet production. It is assumed that in summer most of the planktonic faecal material is disintegrated in the upper water layer and the role of faeces in sedimentation is minor.
\end{abstract}

\section{INTRODUCTION}

"A rain of dead plankton and their faecal material has long been suggested as an important source of food to abyssal communities" (Menzies, 1962). Moreover, sedimentation of pellets was thought to strongly influence vertical distributions of major and minor elements in the sea (Bishop et al., 1977; Spencer et al., 1978) and, for instance, lead to an undersaturation of silica in the water column (Schrader, 1971). This is probably due to high sinking rates of up to over $300 \mathrm{~m} \mathrm{day}^{-1}$ (Smayda, 1969; Turner, 1977; Honjo \& Roman, 1978) measured in vitro.

Small et al. (1973) restricted these high sinking rates to faecal material of greater copepods and euphausiids, and Smetacek (1980) came to the conclusion that microbial breakdown in the water column rather than sedimentation leads to substantial removal of faecal pellets from the water column.

To test this hypothesis for the North Sea, 129 stations were investigated during a voyage in May/June 1986.

\section{MATERIALS AND METHODS}

From May $2^{\text {nd }}$ to June $13^{\text {th }} 1986,129$ stations in the North Sea (Fig. 2) were investigated during a voyage with R.V. "Valdivia". The investigation was part of the project ZISCH ("Zirkulation and Schadstoffumsatz in der Nordsee") carried out by the University of Hamburg.

Several hydrographical and chemical parameters were measured; the following are dealt with in this paper: 
(1) Temperature (ME-Sonde; $\pm 0.01^{\circ} \mathrm{C}$ )

(2) Salinity (ME-Sonde; $\pm 0.001 \mathrm{~S}$ )

(3) Water depth (ME-Sonde; $\pm 0.5 \mathrm{~m}$ )

(4) Chlorophyll (arbitrary units; Turner-fluorometer)

(5) Planktonic faecal pellets

(6) Zooplankton wet weight

For the analysis of planktonic faecal pellets, 5 liters of seawater taken with Niskinbottles in different water-depths were sieved through gauze of $20 \mu \mathrm{m}$ mesh-size, the residue being preserved with $4 \%$ formaldehyd. In the laboratory the samples were analysed with respect to shape, length and width of planktonic faecal pellets under the inverted microscope.

Planktonic faeces were distinguished from benthic faeces (which were relatively numerous near the bottom) by means of shape, colour, form of the tail-piece etc. (Martens, 1972). The volume of the faecal material per liter was computed for each sample as well as the mean length and diameter of the pellets.

For the analyses of zooplankton wet weight, a multiple closing net (Meßhai-system) was chosen to take zooplankton samples according to the different water depths in which faecal pellet samples had been taken. The zooplankton was preserved in $2 \%$ formaldehyd and the wet weight was determined immediately after returning to the laboratory in order to prevent changes due to fixation.

The rate of pellets / zooplankton was computed on the basis of volume / wet weight.

\section{Statistical methods}

A temperature-salinity-diagram (Fig. 1) shows that besides a North Sea water body with a salinity of about $34-35 \mathrm{~S}$, a mixing water body of lower salinity down to $27 \mathrm{~S}$ has been included in the samples. The statistical computations remained confined to the 483 sets of measurements belonging to the North Sea water body.

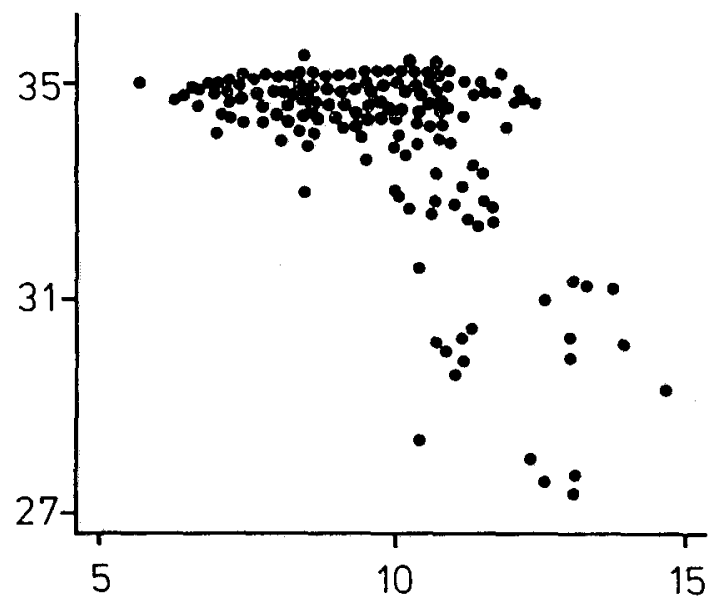

Fig. 1. Temperature-salinity diagram for 539 measurements in the North Sea in May/June 1986. $\mathrm{X}$-axis: temperature in ${ }^{\circ} \mathrm{C} i \mathrm{Y}$-axis: salinity $\mathrm{S}$ 
The sets of data were tested for significant deviations from the normal distribution by means of $\mathrm{Chi}^{2}$-test, KS-test and R/s-test, and log transformed when a better distributionfitting could be achieved.

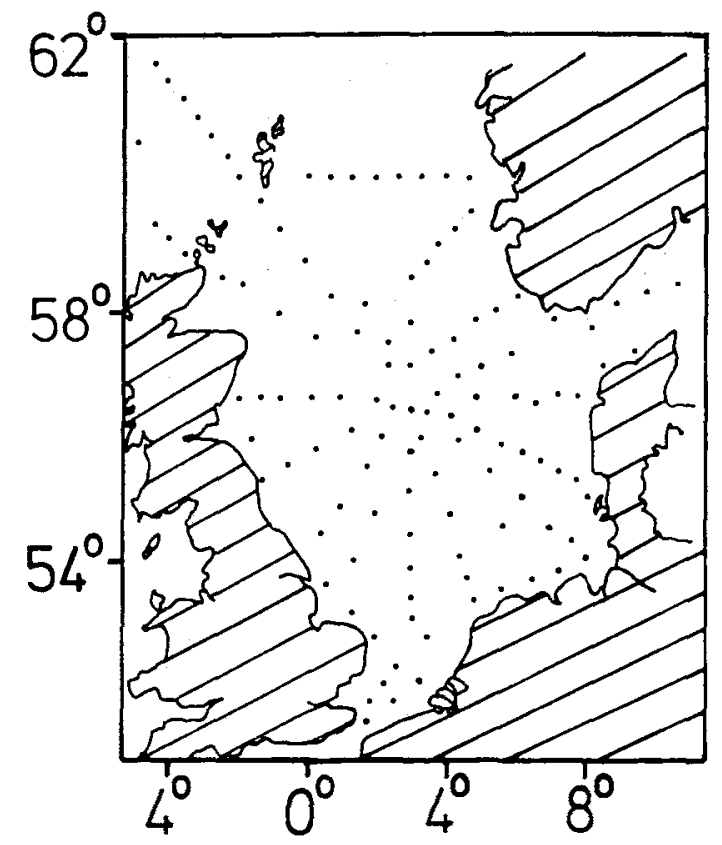

Fig. 2. Stations visited during a voyage in May/June 1986 in the North Sea

To find out by which parameters the amount and size of the faecal pellets had been influenced, a stepwise variable selection was performed. To verify significant results, the partial correlation coefficients between these parameters were determined.

As some of the parameters showed deviations from the normal distribution at least in one method used, Spearman's Rank correlation coefficients were computed.

The statistical analyses were carried out with STATGRAPHICS statistical graphics systems (STSC, 1987) on an Acer 900 under MS-Dos 3.20.

\section{RESULTS}

Figures 3a, b, c show the distribution of faecal pellets on three transects in the North Sea (central station - Shetland Islands, central station - River Tyne, central station Skagerak). What can clearly be seen is an enrichment in the upper water layers.

Figures $4 \mathrm{a}, \mathrm{b}, \mathrm{c}$ show the distribution of zooplankton (wet weight) on the same locations. Maxima of zooplankton occur on stations where great amounts of faecal pellets can be found, although not always at the same depth. The same holds true for chlorophyll (Figs $5 a, b, c$ ). In addition, chlorophyll shows an enrichment in the bottom layers in some cases, which may be due to sedimentation.

Neither zooplankton-biomass nor chlorophyll alone can be held responsible for the 


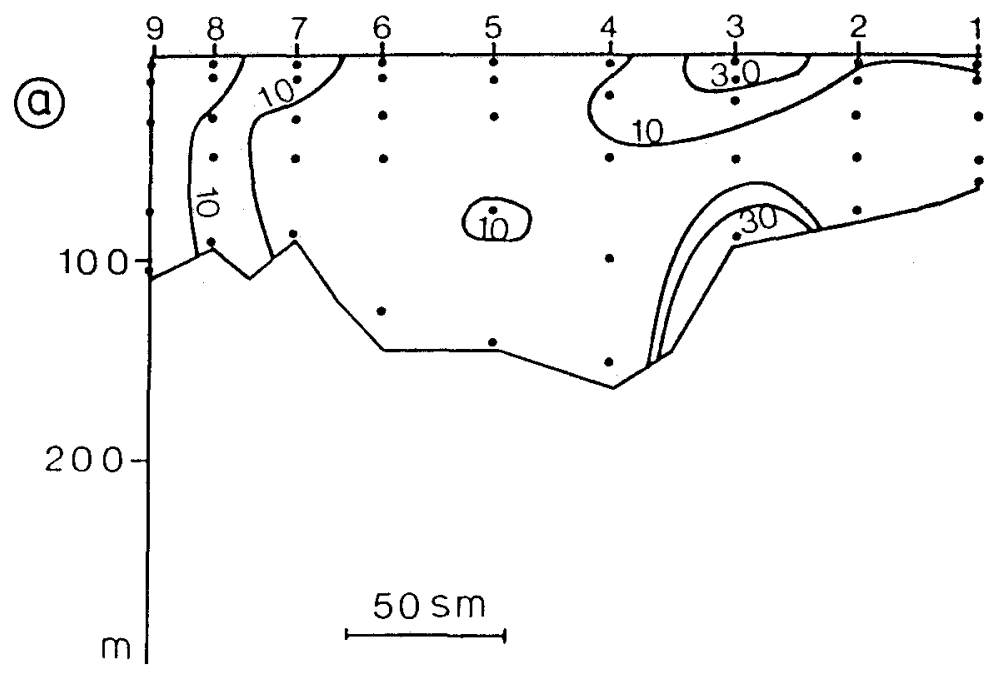

(b)

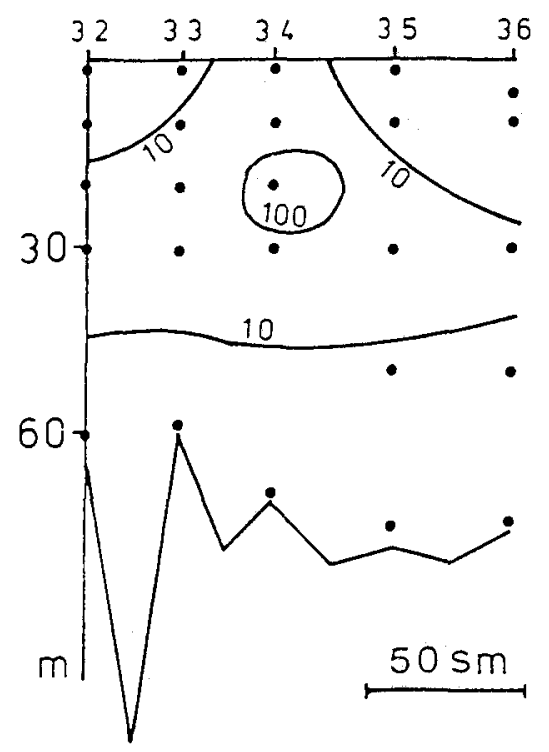

(C)

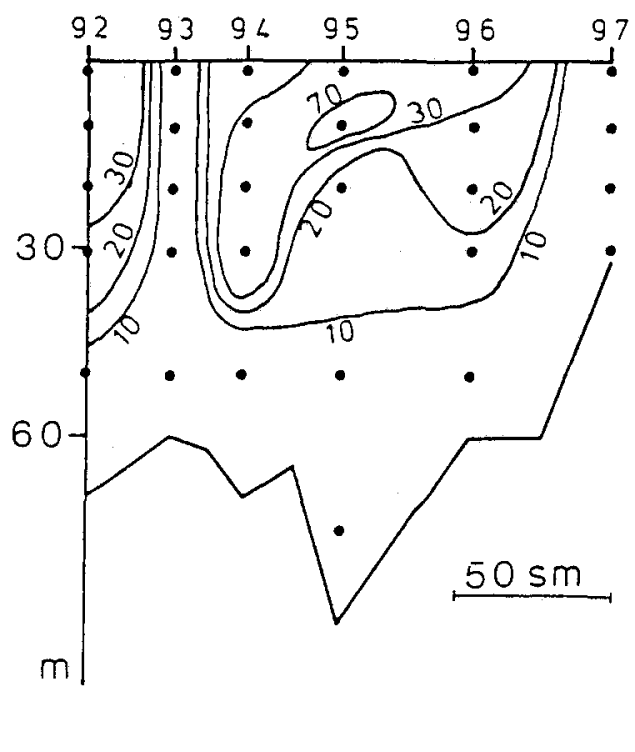

Fig. 3. Isopleth-diagrams for the amount of faecal material $\left({ }^{*} 10^{-6} \mu^{3} \mathrm{dm}^{-3}\right)$ on transects from (a) the central North Sea (1) to the Shetland Islands (9), (b) the central North Sea (36) to the outlet of the River Tyne (32), and (c) the central North Sea (92) to the Skagerak (97). X-axis: stations; Y-axis: water depth in meters 
(a)

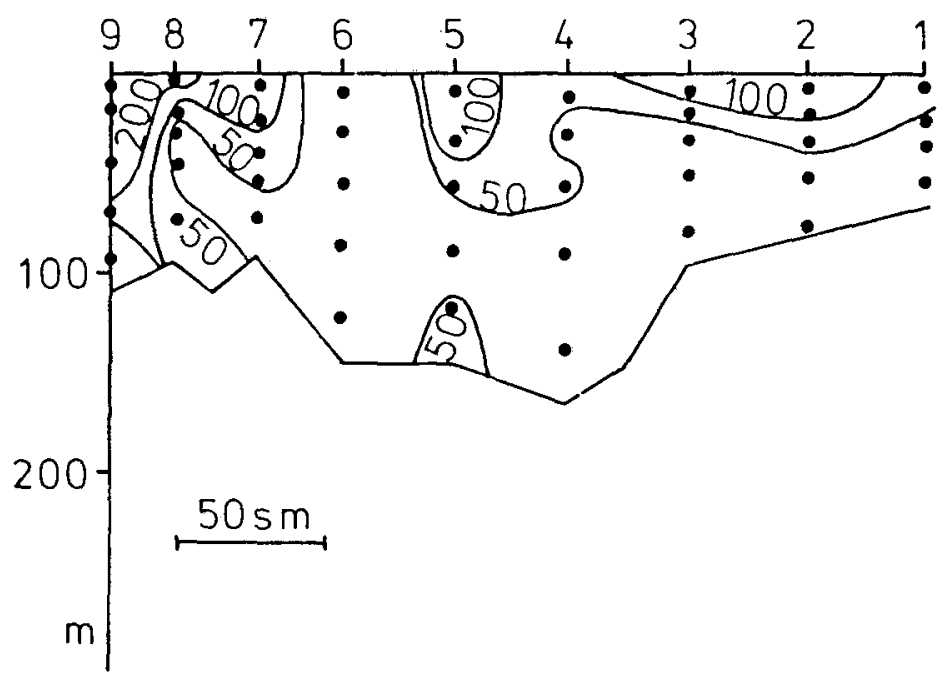

(b)

(C)
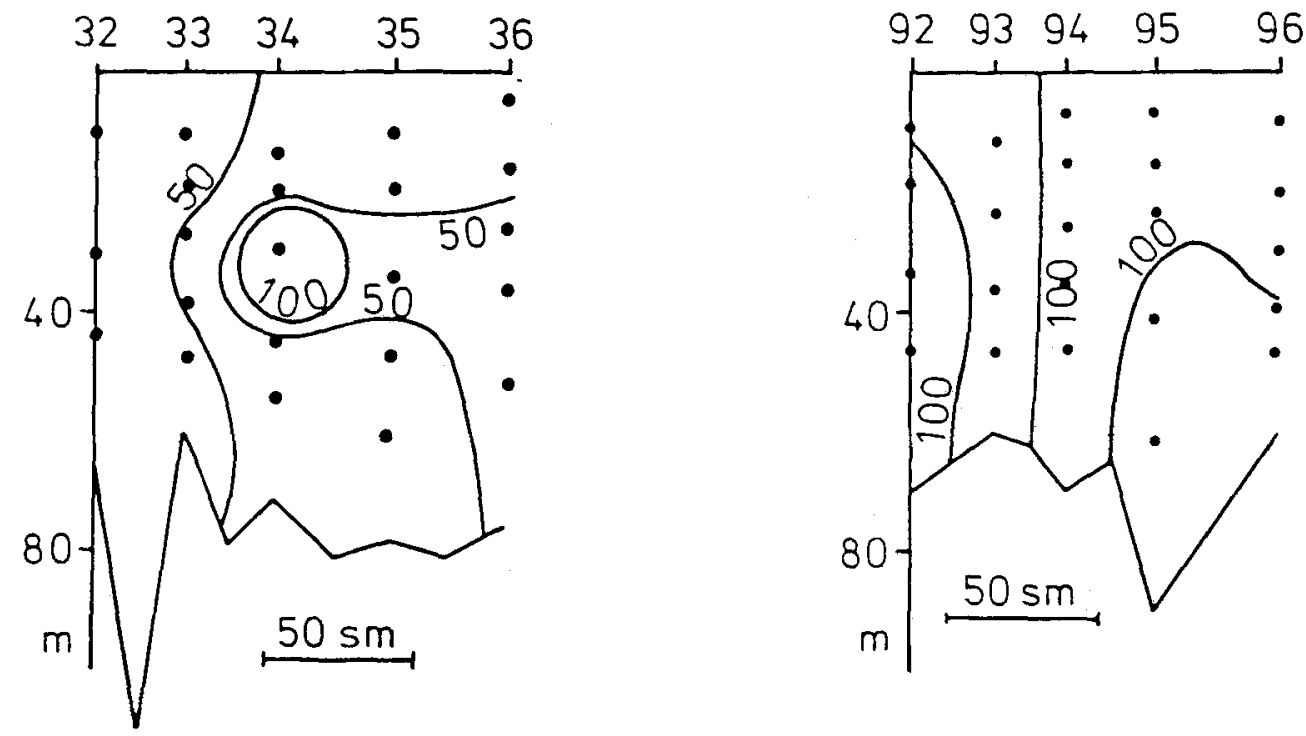

Fig. 4. Isopleth-diagrams for the amount of zooplankton $\left(\mu \mathrm{g} \mathrm{dm}^{-3}\right)$ on transects from (a) the central North Sea (1) to the Shetland Islands (9), (b) the central North Sea (36) to the outlet of the River Tyne (32), and (c) the central North Sea (92) to the Skagerak (97). X-axis: stations; Y-axis: water depth in meters 
(a)

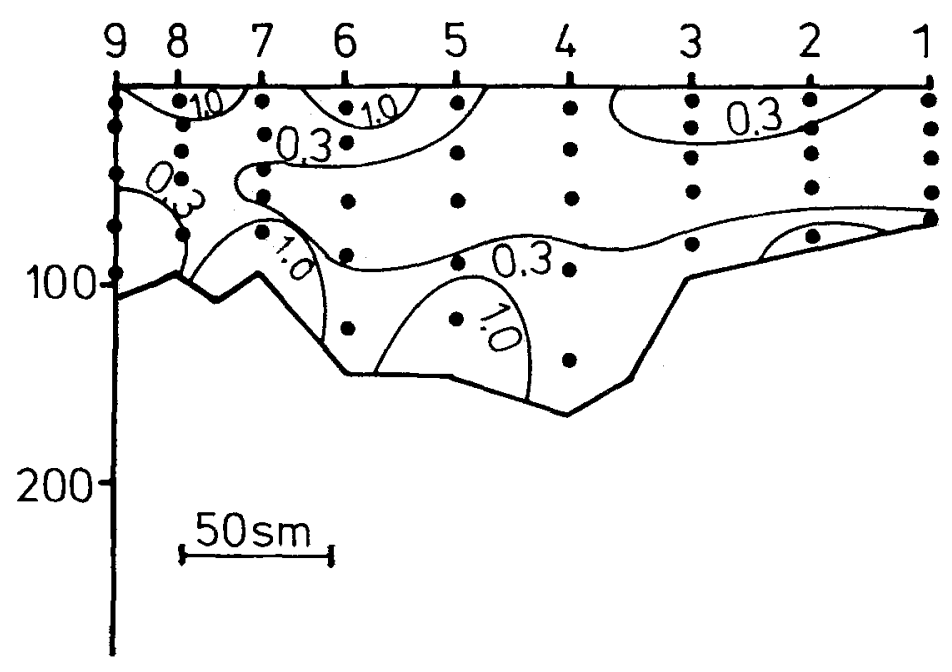

(B)

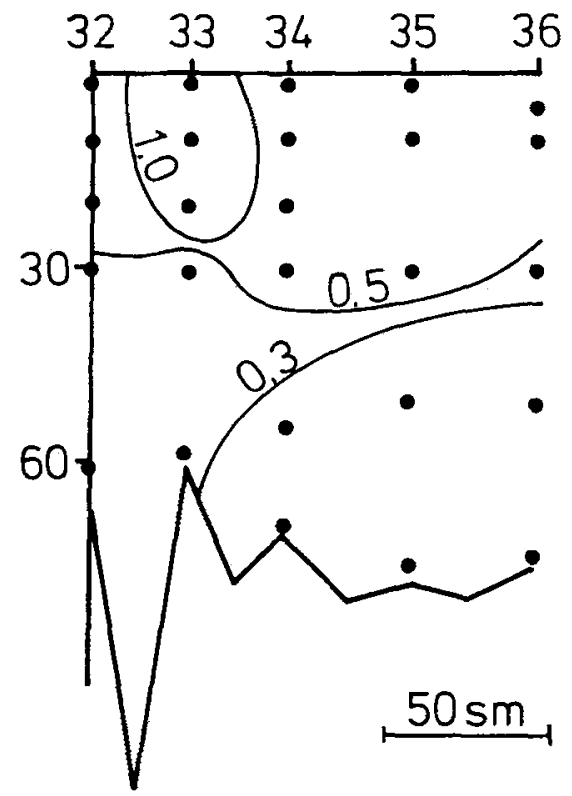

(C)

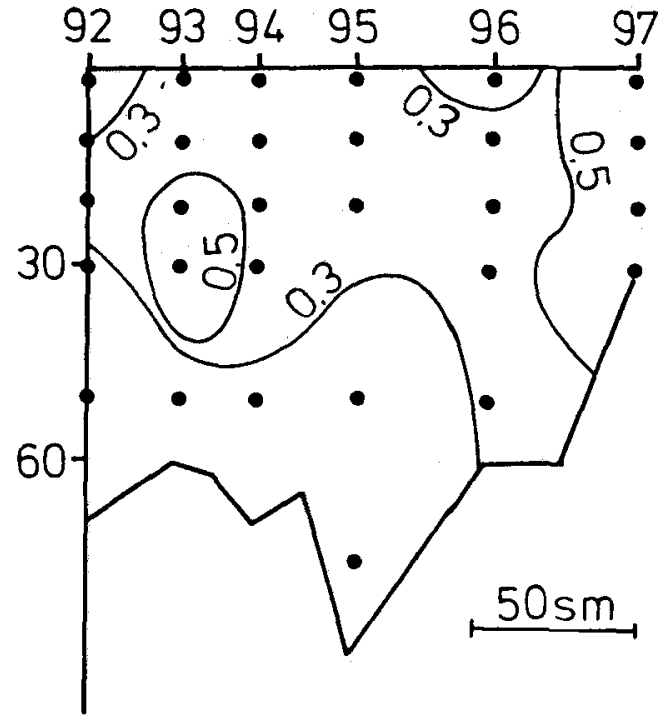

Fig. 5. Isopleth-diagrams for the amount of chlorophyll (arbitrary units) on transects from (a) the central North Sea (1) to the Shetland Islands (9), (b) the central North Sea (36) to the outlet of the River Tyne (32), and (c) the central North Sea (92) to the Skagerak (97). X-axis: stations; Y-axis: 
distribution of the faecal material, as can be seen from the comparison of the different figures. These multiple interrelationships between faeces, producers and food could be confirmed by statistical methods. Table 1 shows the results of the stepwise variable selection for the amount of faeces, the length and the diameter of the pellets. The only parameters which are of significant influence on the amount of faeces are the amounts of zooplankton and of chlorophyll, i.e. producers and food.

Table 1. List of factors of significant influence $(\mathrm{P}<0.05)$ on the different parameters measured derived from a stepwise variable selection. $t=$ Regression coefficient/standard error; $s l=$ significance level for the t-value (the probability that a larger absolute t-value would occur if there were no marginal contribution from that parameter)

\begin{tabular}{|llrr|}
\hline Parameter & Factor & $\mathrm{t}$ & \multicolumn{1}{c|}{ sl } \\
\hline \multirow{2}{*}{ Amount of pellets } & Chlorophyll & 10.09 & $<0.0001$ \\
& Zooplankton & 10.41 & $<0.0001$ \\
& Water depth & -2.50 & 0.0127 \\
& Temperature & -6.49 & $<0.0001$ \\
& Salinity & 3.37 & 0.0008 \\
& Chlorophyll & 6.83 & $<0.0001$ \\
& Zooplankton & 6.25 & $<0.0001$ \\
& Temperature & -2.90 & 0.0039 \\
& Salinity & 8.55 & $<0.0001$ \\
& Chlorophyll & 3.52 & 0.0005 \\
Faeces/zooplankton & Chlorophyll & 5.19 & $<0.0001$ \\
& Daytime & 2.01 & 0.0455 \\
\hline
\end{tabular}

The diameter of the faeces is related to temperature, salinity and chlorophyll, whereas in pellet-length an additional influence of zooplankton wet weight and water depth shows up. There is a negative relationship between pellet-length and water depth - in greater depths the pellets become shorter.

These results could be confirmed by partial correlation analyses (Table 2) showing the correlations between the different parameters when the influence of the others is excluded. The non-parametrical Spearman-Rank correlation analyses gave the same results (Table 3 ).

As shown bei Table 1, the ratio of pellets to zooplankton is influenced by chlorophyll and by daytime. Spearman's Rank correlation analysis does not confirm the latter. The influence of this parameter is masked by other factors which are excluded in the partial correlation analysis, where the influence of daytime shows up.

\section{DISCUSSION}

The analyses of the faecal material under the inverted microscope gave one result which could hardly be expressed in terms of statistics but made these almost superfluous: The deeper the samples were taken, the more "destructed" were the faecal pellets. Pellets from deeper water looked rotten, or, as Smetacek (1980) mentioned: "The breakdown rate in the water column appears to be rapid...". Below $100 \mathrm{~m}$ water depth 

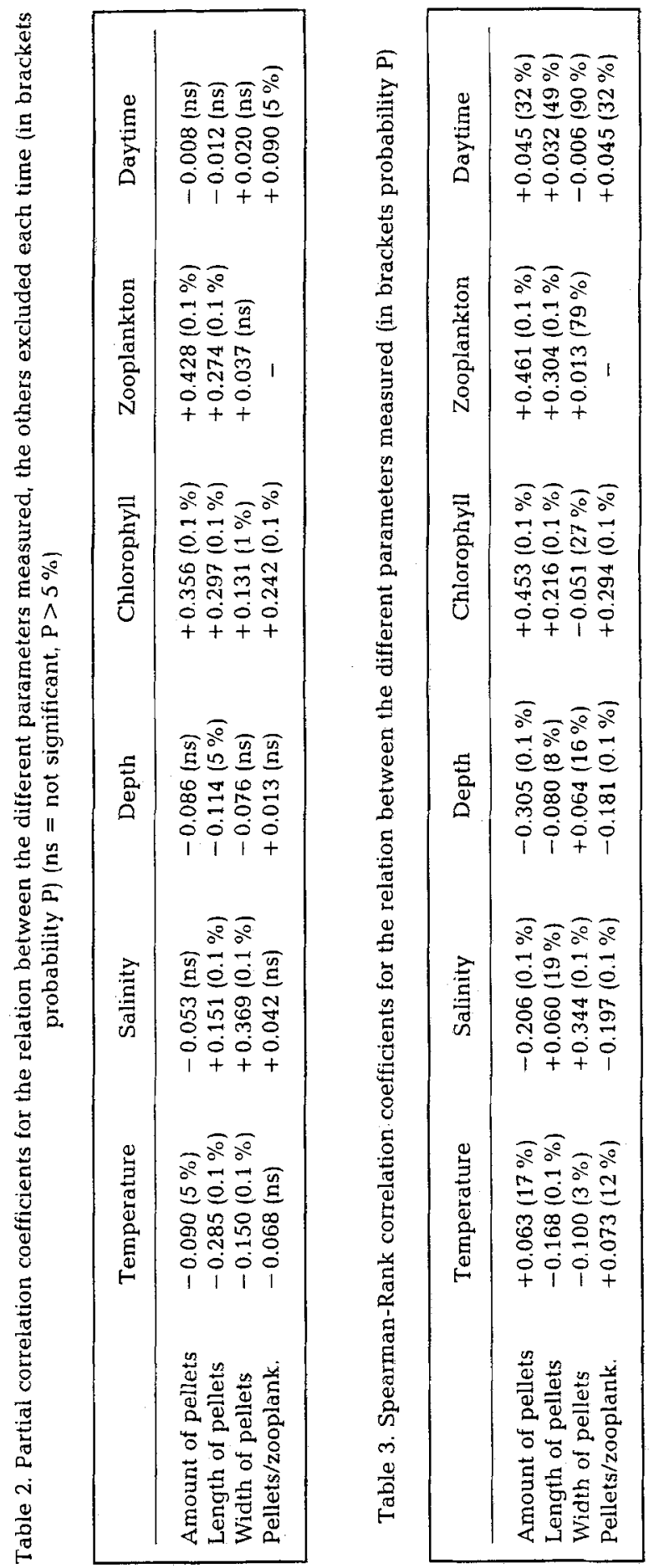
nearly no formed faecal material could be found. This could be proven by statistical computations.

No direct influence of the water depth on the amount of faecal material could be verified. Faeces-volume is correlated to the amount of zooplankton and food (chlorophyll) which has been shown earlier (Marshall \& Orr, 1972; Gaudy, 1974; Honjo \& Roman, 1978; Paffenhöfer \& Knowles, 1979). The direct relation between faeces and their producers is not as self-evident as it may look at first sight. A diurnal migration of the zooplankton with, for example, defaecation in the upper water layer could lead to an inverse relationship between faeces and zooplankton. A rapid sedimentation of the faeces could bring the same result. However, this is not the case. The maximum of the faecal material is where the producers are. The more food is available, the more faeces are produced.

An influence of the water depth shows up when looking at the mean length of the faeces. Again, a positive influence of food can be seen. The correlation with zooplanktonbiomass and salinity (which shows up in the mean diameter as well) is probably due to the fact that large copepod species such as Calanus finmarchicus s.l. form the mass of the animals at stations with higher amount of zooplankton (Krause, unpubl. data). These copepods, which produce relatively large pellets, prefer water of higher salinity.

Water temperature is negatively correlated with the pellet length as well as the diameter of the pellets, water depth negatively with the length. As shown by Honjo \& Roman (1978) and Turner (1977), temperature significantly influences biodegradation the higher the temperature, the faster the pellets break into pieces when sinking to deeper water layers. Steele \& Baird (1972) could show degradation of faecal pellets even in a $30 \mathrm{~m}$ water column. This might be due to the fact that the protective pellet outer membrane is degraded by microbial activity in 3 hours at $20^{\circ} \mathrm{C}$ (Honjo \& Roman, 1978). This is supported by Smetacek (1980) who found residence times of pellets in Kiel Bight in spring and summer of only few hours.

Zooplankton is suggested to egest about $15 \%$ of its weight as faeces per day (Petipa et al., 1970). The ratio of faecal pellets to zooplankton is a result of the relationship between production rate and residence time of the faecal pellets in the water column. $\mathrm{A}$ relation of faeces to zooplankton much greater than 0.15 could be caused by a much higher defaecation rate or by a very slow degradation rate and slow sinking rate causing accumulation of faeces in the upper water layers.

A relation much lower than 0.15 would, on the other hand, be a sign of decomposition of the faecal pellets, as a much lower feeding rate (which could lead to a lower defaecation rate) is unlikely - the animals need high amounts of food during the season of maximum reproduction.

Maximum values of more than 0.5 can be found during this investigation (Fig. 6) but the average ratio is 0.03 . Below $100 \mathrm{~m}$ water depth it decreases rapidly. This surplus of animals compared with faecal material in deep water is another sign of a massive decrease of the pellets.

The ratio of faecal pellets to zooplankton (which consisted mainly of copepods; Krause, unpubl. data) was influenced by food concentration as shown earlier by Smetacek (1980). The other parameter of significant influence $(P>5 \%)$ was the time of day at which the samples were taken, indicating a diel rhythm in defaecation. Such diel rhythms in zooplankton have been shown earlier for the North Sea (Krause, 1981; Martens, 1986; etc.). 


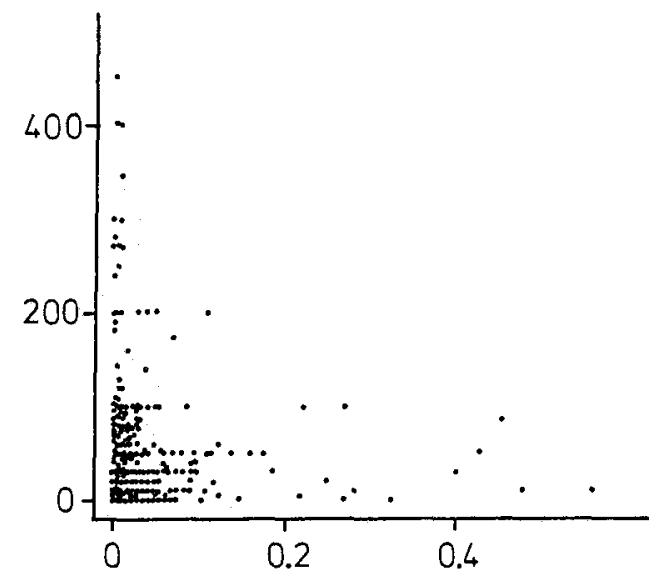

Fig. 6. The ratio of faecal pellets to zooplankton (X-axis) versus the water depth (Y-axis) for 483 measurements during a voyage in May/June 1986 in the North Sea

All these results can be summarized as follows: The amount of faecal pellets is related to the amount of food available and to the amount of producers (zooplankton). A massive breakdown occurs in the upper water layer influenced by temperature. A diel rhythm can be found in the relation of faeces to zooplankton. Beneath $100 \mathrm{~m}$ water depth, hardly any formed faecal material can be found; remineralisation of the pellets in summer takes place in the upper water layer, so, as Smetacek (1980) says: "Grazing of phytoplankton by neritic zooplankton will thus not necessarily result in the rapid depletion of material, particularly essential nutrients, from the euphotic zone."

Acknowledgements. We should like to thank the captain and the crew of R. V. Valdivia for the excellent technical support even during periods of very rough weather, and P. König (DHI) for the data on temperature, salinity and chlorophyll.

\section{LITERATURE CITED}

Bishop, J. K., Edmond, J. M., Ketten, D. R., Bacon, M. P. \& Silker, W. B., 1977. The chemistry, biology and vertical flux of particulate matter from the upper $400 \mathrm{~m}$ of the equatorial Atlantic Ocean. Deep Sea Res. 24, 511-548.

Gaudy, R., 1974. Feeding four species of pelagic copepods under experimental conditions. - Mar. Biol. 25, 125-141.

Honjo, S. \& Roman, M. R., 1978. Marine copepod fecal pellets: production, preservation and sedimentation. - J. mar. Res. 36, 45-57.

Krause, M., 1981. Vertical distribution of faecal pellets during FLEX 76. - Helgoländer Meeresunters. $34,313-327$.

Marshall, S. M. \& Orr, A. P., 1972. The biology of a marine copepod, Oliver \& Boyd, London, $195 \mathrm{pp}$.

Martens, P., 1972. Zur Charakterisierung der Kotballen von vier dominierenden Copepodenarten der Kieler Bucht. Diss., Univ, Kiel, $106 \mathrm{pp}$.

Martens, P., 1986. Diurnal variation in the respiration rate of natural zooplankton communities in the North Sea. - Oebalia 13, 201-219.

Menzies, R. J,, 1962. On the food and feeding habits of abyssal organisms as exemplified by the Isopoda. - Int. Revue ges. Hydrobiol. 47, 339-358. 
Paffenhöfer, G. A. \& Knowles, S. C., 1979. Ecological implications of fecal pellet size, production and consumption of copepods. - J. mar. Res. 37, 35-49.

Petipa, T. S., Pavlova, E. V. \& Mironov, G. N., 1970. The food web structure, utilization and transport of energy by trophic levels in the planktonic communities. In: Marine food chains. Ed. by J. $\mathrm{H}$. Steele. Oliver \& Boyd, Edinburgh, 142-167.

Schrader, H.-J., 1971. Fecal pellets: role in sedimentation of pelagic diatoms. - Science, N.Y. 174, 55-57.

Small, L. F. \& Fowler, S. W. 1973. Turnover and vertical transport of zinc by the euphausiid Meganyctiphanes norvegica in the Ligurian Sea. - Mar. Biol. 18, 284-290.

Smayda, T. J., 1969. Some measurements on the sinking rate of fecal pellets. - Limnol. Oceanogr. 14, 621-626.

Smetacek, V. S., 1980. Zooplankton standing stock, copepod faecal pellets and particulate detritus in Kiel Bight. - Estuar. coast. mar. Sci. 11,477-490.

Spencer, D. W., Brewer, P. G., Fleer, A., Honjo, S. Krishnaswami, S. \& Nozaki, Y., 1978. Chemical fluxes from a sediment trap experiment in the deep Sargasso Sea. - J. mar. Res. 36, 492-523.

Steele, J. H. \& Baird, I. E., 1972. Sedimentation of organic matter in a Scottish sea loch. - Memorie Ist. ital. Idrobiol. 29 (Suppl.), 73-86.

STSC, 1987. STATGRAPHICS, Statistical Graphics Systems. STSC Inc., Rockville, 743 pp.

Turner, J. T., 1977. Sinking rates of fecal pellets from the marine copepod Pontella meadii. - Mar. Biol. 40, 249-259. 